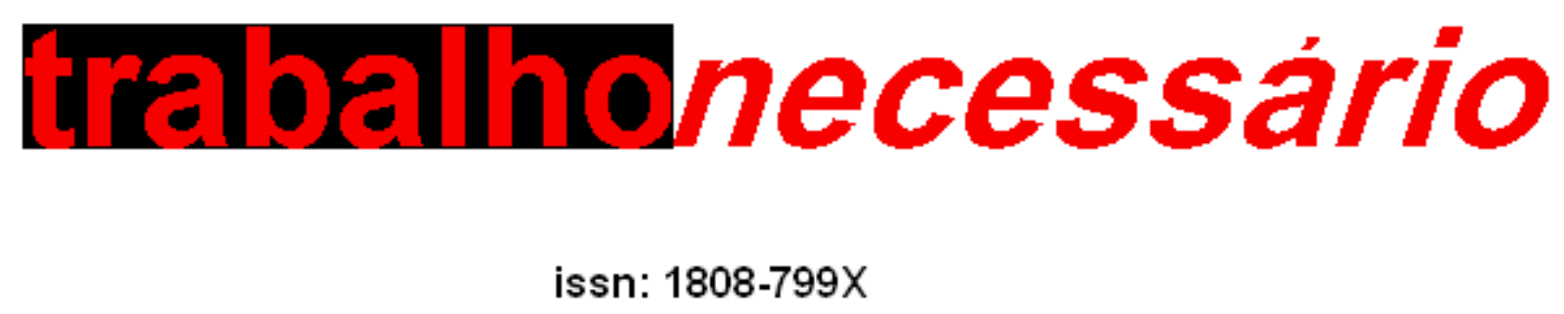

ano 4 - número 4 - 2006

\title{
O TRABALHO INFORMAL DESLOCADO DA ECONOMIA PARA A ASSISTÊNCIA SOCIAL[1]
}

Maria Augusta Tavares[2]

Não é novidade que o capital vive uma das suas crises de superprodução. Manterse enquanto forma social dominante implica liberdade suficiente para desmantelar as estruturas do Estado Social, o que vem acontecendo, especialmente na última década, através das políticas de privatização, desregulamentação e liberalização.

Nesse contexto, torna-se imprescindível a redivisão social do trabalho, a reestruturação produtiva e o neoliberalismo. Essas são determinações de uma forma de produção de mercadorias que, segundo Teixeira (2000), só pode se afirmar se essas condições se fizerem presentes. $O$ desdobramento dessas condições se expressa no Programa de Ajuste Estrutural (PAE), que, orientado pelos princípios do laissez-faire, privilegia a eficiência, a produtividade, o comércio e a troca internacional, penalizando profundamente a classe trabalhadora, especialmente as camadas mais pobres dos países periféricos.

Sob tais princípios, tudo é produzido para o mercado. Até os serviços públicos devem cumprir a lógica da eficiência. Entretanto, contraditoriamente, instituições financeiras internacionais (IFIs), da estatura do Banco Mundial e do Fundo Monetário Internacional (FMI) apresentam um repentino interesse pelo "setor informal" (Addison \& Demery, 1987), recomendando a sua expansão como uma ação complementar às políticas de assistência. Como a racionalidade do mercado é o critério de justiça das instituições financeiras, procede perguntar: a expansão do "setor informal" é uma ação complementar às políticas de assistência ou uma estratégia de organização da produção capitalista ?

$\mathrm{Na}$ ordem burguesa, as determinações ideológicas fundadas no liberalismo são portadoras de oportunismos capazes de atribuir status completamente diferentes a um mesmo fenômeno, a depender do estágio do desenvolvimento econômico. A propósito, é o que acontece com o "setor informal". 
Quando o capitalismo partilhava a idéia de que a sua organização produtiva, regulada pelo livre mercado, se expandiria de forma equilibrada, homogênea e integradora, o "setor informal" era visto como sinônimo de atraso. Sob este enfoque, o desenvolvimento do capital acabaria por eliminá-lo. Mas, quando a mesma economia de livre mercado se revela incapaz da integração prometida, o "setor informal" se impõe como a forma mais adequada à solução do desemprego, sendo reivindicado não porque o seu desempenho contribua para a acumulação capitalista, mas como uma ação complementar às políticas de assistência.[3]

Esse deslocamento do desenvolvimento para a luta contra a pobreza, além de separar o econômico do social, faz supor que as atividades informais se restringem apenas a estratégias de sobrevivência, o que obscurece as relações existentes entre o "setor informal" e o núcleo formal da economia. Em outras palavras, a acumulação flexível tenta esconder relações que articulam mais-valia absoluta e mais-valia relativa, mediante uma rearrumação de formas pretéritas da produção de mercadorias, nas quais se inscrevem cooperativas de trabalho, trabalho domiciliar, empresas familiares, e tantas outras formas de trabalho precário, que os liberais conseguem enxergar como espaços de autonomia e de independência do trabalhador.

Diferentemente do que pensam os apologistas do capital, apreendemos o setorialismo da economia como um dos equívocos decorrentes da razão dual. Entendemos que a verdade está no todo, na totalidade. Embora esta palavra esteja cercada de impopularidade, convergimos com Lukács, quando diz que "A categoria da totalidade, como toda a categoria autêntica, reflete relações reais" (1960: 282). E complementa:

"A categoria da totalidade significa, pois, por um lado, que a realidade objetiva é um todo coerente de que cada elemento está de uma maneira ou outra em relação com cada outro elemento e, por outro lado, que essas relações formam na própria realidade objetiva, correlações concretas, conjuntos, unidades, ligadas entre si de maneiras inteiramente diversas, mas sempre determinadas" (Idem: 282-283).

Nesta perspectiva, seria uma incoerência falar de setor. Com isso, não estamos cancelando as atividades de sobrevivência, que não se articulam diretamente à produção capitalista. Mas, isso não implica um setor. Todas as formas de organização da produção, mesmo as que não podem ser consideradas expressões claras de relações capitalistas, estão submetidas às determinações do capital, sejam elas amparadas pela lei ou exercidas na clandestinidade. Portanto, ao invés de falar de "setor informal", vamos discutir o trabalho informal no interior do modo de produção capitalista. Ou seja, analisamos a informalidade a partir das relações de trabalho, como sugere Lautier (1991), e não como se cada trabalhador informal fosse um pequeno empresário. Transformar todo trabalhador por conta própria em empresário é uma estratégia que, em certos casos, serve para ocultar processos de extração de mais-valia, uma vez que em lugar de uma relação que se 
efetiva na esfera da produção, o que se tem, ou melhor, o que aparece é uma relação entre comprador e vendedor de mercadoria, que se consubstancia tão-somente na esfera da circulação. Contudo, deve ficar claro que mesmo quando se trata de pequenos patrões, comuns no chamado "setor informal", o fato de serem empregadores não os torna capitalistas. Para Marx,

"Certo grau de desenvolvimento da produção capitalista exige que o capitalista possa aplicar todo o tempo, durante o qual funciona como capitalista, isto é, como capital personificado, à apropriação e, portanto ao controle do trabalho alheio e à venda dos produtos deste trabalho" (1983: 243).

Em outras palavras: "Os meios de produção só se tornam capital, ao ficarem independentes, como força autônoma do trabalho" (Marx, 1980: 402). O fato de um indivíduo ser proprietário de alguns meios de produção, pelos quais consegue oferecer alguns empregos informais, não faz dele um capitalista. O proprietário de meios de produção numa escala em que continua dependente do trabalho, é um meio-termo entre assalariado e capitalista, podendo, às vezes, trabalhar muito mais do que se fosse um simples assalariado. Em termos capitalistas, "Não é o trabalho que utiliza os meios de produção; são os meios de produção que utilizam o trabalho" (Idem, 1978: 19). É o capital quem emprega trabalho, e nada se produz fora do relacionamento capitalista. $\mathrm{Na}$ proporção em que se consolida o desenvolvimento tecnológico cada vez mais os trabalhadores são substituídos, subjugados e tornados supérfluos nas formas independentes. (Marx, 1980: 386) Portanto, não tenhamos a ingenuidade de pensar que os efeitos desse enfrentamento desigual é preocupação para o capital, como quer nos fazer crer o Banco Mundial e o FMI.

Embora o emprego formal já não tenha a mesma centralidade na sociedade capitalista, a matriz Estado-empregadores-assalariados permanece sendo o paradigma para a reprodução do capital. Se indivíduos da classe trabalhadora não conseguem vender a sua força de trabalho, só lhes resta a possibilidade de encontrar os seus meios de subsistência mediante uma atividade por conta própria. Mas isso não quer dizer que este trabalhador tem autonomia, nem que foi, necessariamente, transformado num vendedor de mercadoria. Em certos casos, especialmente mediante a prática da terceirização, muitos trabalhos informais se articulam por fios invisíveis à produção formal. Ou seja, há uma fração moderna do trabalho informal, que longe de ser uma atividade à margem do núcleo formal da economia, participa diretamente do processo de acumulação do capital, como é o caso de indústrias nacionais e internacionais que utilizam o trabalho domiciliar como parte do trabalho coletivo. Tal relação implica, geralmente, mais sobretrabalho sem os custos sociais correspondentes para o capital.

A nosso ver, classificar o trabalho informal como mera atividade de sobrevivência é mais um embuste da ordem burguesa, tendo em vista deslocar a discussão da 
informalidade que é funcional à economia flexível, para localizá-la tão-somente no interior do que não é trabalho produtivo nem improdutivo, na perspectiva marxista. Organismos financeiros internacionais, através de organizações não-governamentais (ONGs), têm participado, embora de forma modesta, de programas sociais para os extremamente pobres, nos quais se oferece incentivo ao que denominam atividades informais. Mas, tais programas, ao invés da pretensa proteção social, têm por objeto conter os ânimos das populações despossuídas que se organizam, podendo pôr em risco as políticas de ajustamento.

Cabe, então, observar o que propõe Lautier: "que é do trabalho assalariado que é preciso partir para se perguntar porque, em certos casos há a observância da legislação e em outros não". (1991: 24) O cotejamento desta concepção com o discurso das IFIs, suscita a nossa questão inicial: o "setor informal" é uma forma de proteção social ou uma forma de organização da produção capitalista adequada à acumulação flexível? Dada a insustentabilidade da idéia de setor, cabe refazer a pergunta em outros termos: o produto do trabalho informal é reduzível a valor de troca?

Ora, o trabalho informal é comumente identificado com autonomia, como se fosse possível, numa economia inteiramente dominada pelo capital, haver alguma organização autônoma do trabalho. Para ser valor de troca, o trabalho informal tem que ser trabalho abstrato, portanto diretamente subordinado à relação capital. Uma relação possui dois termos. No caso do trabalho formal, é fácil verificá-la, uma vez que existe, de um lado, o patrão, que corporifica o capital e, do outro, o empregado, corporificando o trabalho. Mas, quando se trata do trabalho informal, como não existe a personificação do comando representada por um indivíduo, tem-se a impressão de que há ali um espaço de autonomia. Poderíamos dizer que a relação se dá com o mercado, ou com o capital, contudo, isso não daria conta de todas as contradições que dão forma e conteúdo a essa relação social. Compreendê-la, portanto, implica o desenvolvimento de mediações que nos permitam chegar ao conceito de capital.

Com esse propósito, tentaremos seguir o caminho feito por Marx, segundo o qual, "Para chegar ao conceito de capital é necessário partir do valor e não do trabalho, e concretamente do valor de troca desenvolvido no movimento da circulação" (1989:198). Esclarece Teixeira:

"Nessa determinação histórica, pode-se afirmar que capital é trabalho acumulado. Mas é preciso esclarecer que esse trabalho assim acumulado é trabalho criador de valor que busca se valorizar. Valor que cria mais valor. Portanto, o conceito de capital não pode ser derivado diretamente do trabalho, e sim do valor, visto que este é a forma assumida pelo trabalho na sociedade capitalista. Essa forma social (formal), por sua vez, exige uma forma material (fenomênica) adequada por meio da qual o valor ganha existência. Essa forma é o valor de troca ou o dinheiro, expressão necessária de aparição do valor" (1985: 127). 
É esta forma valor que permite equiparar diferentes espécies de mercadorias, reduzindo-as ao que elas têm em comum: trabalho humano abstrato. Abstraindo-se o valor de uso das mercadorias $3 / 4$ suporte para o valor de troca $3 / 4$ "resta a elas apenas uma propriedade que é a de serem produtos do trabalho" (Marx, 1983: 47). Ali não se identifica mais o produto deste ou daquele trabalhador. O valor, essa "substância social comum", exclui os sujeitos que produzem e a forma como são produzidas as mercadorias, restando ali somente "uma simples gelatina de trabalho humano indiferenciado" (Idem: 47). O trabalho humano concreto, "eterna necessidade do homem", torna-se tão-somente trabalho humano abstrato, ou seja, suas propriedades naturais são dissolvidas em algo que é social.

Nesse contexto, em que a força conjunta do trabalho é uma única e mesma força humana, conclui-se que toda a força produtiva é força produtiva do capital. Seja qual for o tipo de trabalho, o comando é do capital. E não é assim por um ato de vontade dos capitalistas, mas por determinações estruturais do próprio sistema. Desde que o processo produtivo deixou de ser processo simples do trabalho e tornou-se um processo científico, todas as forças produtivas do trabalho, desenvolvidas a partir do trabalho social, aparecem como força produtiva do capital. O trabalhador individual é tão somente um elemento dessa formação social e, enquanto parte de uma formação que não lhe pertence, torna-se impotente para produzir de forma autônoma.

Mas não estamos afirmando que todo trabalho é produtivo para o capital, isto é, que todo trabalho produz mais-valia, e menos ainda, que todo trabalho faz parte do trabalho coletivo. $O$ trabalho coletivo pressupõe produtividade, mas implica, também, "a combinação social, na qual as diversas forças de trabalho funcionam tão-somente como órgãos particulares da capacidade de trabalho que constitui a oficina coletiva" (Marx, 1978: 83). O que estamos afirmando efetivamente é que o processo global de desenvolvimento da acumulação capitalista não depende apenas do trabalho produtivo. $O$ ciclo dinheiromercadoria -dinheiro ( $D-M-D)$, fórmula universal do capital, só é possível, mediante a relação dialética do trabalho produtivo com o improdutivo. Com esta argumentação, pretendemos retomar a particularidade do nosso objeto $3 / 4$ o trabalho informal $3 / 4$, no sentido de evidenciar certas determinações postas pela reestruturação produtiva do capital, especificamente no que se refere ao uso crescente dessa forma de trabalho, ora assumindo funções de trabalho produtivo, ora, de improdutivo.

A partir dessa constatação, é preciso rejeitar a idéia de um trabalho informal independente que se restringe às atividades de estrita sobrevivência, sem qualquer participação no processo de valorização do capital. Graças à desregulamentação do trabalho, os contornos entre produtivo e improdutivo, e entre formal e informal são bastante tênues. Deve-se atentar para o fato de que, contemporaneamente, certas atividades desenvolvidas através de relações informais cumprem a mesma função que, quando 
realizada formalmente, tornava explícita a produção de mais-valia agora obscurecida. É inegável a existência de ocupações informais na esfera de estrita sobrevivência, mas há, também, relações como a do trabalho domiciliar, e das cooperativas de trabalho, subcontratadas por grandes empresas capitalistas, sem que os trabalhadores tenham direito a qualquer proteção social, embora lhes sejam impostas obrigações idênticas à relação em que há compra/venda da força de trabalho.

No Brasil, por exemplo, isso ocorre com costureiras que trabalham para indústrias de confecção no Rio de Janeiro (Ramalho, 1998) e com outras que trabalham para um grupo de investidores do Taiwan, instalado no interior do Ceará[4] (Moreira, 1999). Há ainda, dentre muitas outras práticas de trabalho "flexível", profissionais que trabalham para as indústrias de calçados, no Sul do país, para não citar as multinacionais. São majoritariamente mulheres, cujas responsabilidades com a família eliminam outras alternativas de emprego, o que as obriga a aceitarem salários e condições de trabalho não regulados, apesar do produto do seu trabalho ser parte da moderna economia. Fica fácil deduzir que, essa e outras formas de trabalho, onde a deslocalização é ressaltada como vantagem, ao invés de proteger o trabalhador, permite ao capital tirar proveito de fatores de natureza social resultantes da sua própria dinâmica.

Por isso, o apoio ao trabalho informal por instituições financeiras internacionais deve ser questionado. Sem queremos atribuir ao trabalho informal um status que ele ainda não tem, há que se considerar os indícios de uma tendência à generalização. Aqui e agora, o que se quer é deixar claro que consideramos uma incorreção tratar o trabalho informal como complemento às políticas de assistência, mesmo que, sob essa ótica, se restrinja às ocupações de estrita sobrevivência. Enxergar o desenvolvido como parte da economia capitalista e o atrasado como não-capitalista é esquematizar a sociedade, a partir de uma perspectiva que não resiste à prática nem à história. Sob o ângulo da totalidade, o que se apreende é que o núcleo formal da economia, graças à sua "capacidade" de criar mecanismos para dissimular a ilegalidade, dela faz uso, tornando o trabalho informal cada dia mais funcional à acumulação capitalista.

\section{REFERÊNCIAS BIBLIOGRÁFICAS}

ADDISON T \& DEMERY, L. The alleviation of poverty under structural adjustment, Washington, D.C., The World Bank, 1987.

LAUTIER, B. L'État et l'informel. Paris, Editions L'Harmattan, 1991.

LUKÁCS, G. Realismo e existencialismo. Lisboa, Arcádia, 1960.

MARX, K. O capital. São Paulo, Abril Cultural, 1983.

Teorias da mais-valia. Rio de Janeiro, Civilização Brasileira, 1980.

Capítulo VI (Inédito) São Paulo, Ciências Humanas, 1978. 
. Elementos fundamentales para la crítica de la economia política (Borrador) 1857-1858. Buenos Aires, Siglo XXI, 1989, Vol 1.

MOREIRA, M. V. C. Cooperativismo e desenvolvimento: o caso das cooperativas de confecções do Maciço de Baturité, Ceará. In: TEIXEIRA, F. J. S. et alli. Globalização e mercado de trabalho no Estado do Ceará. Fortaleza, UNIFOR, 1999.

RAMALHO, J. R. Precarização do trabalho e impasses da organização coletiva no Brasil. In: ANTUNES, R. (Org.) Neoliberalismo, trabalho e sindicatos. São Paulo, Boitempo, 1998.

SALAMA, P. \& VALIER, J. Pobreza e desigualdades no $3^{\circ}$ mundo. São Paulo, Nobel, 1997.

TEIXEIRA, F. J. S. Pensando com Marx. São Paulo, Ensaio, 1995.

O capital e suas formas de produção de mercadorias: rumo ao fim da economia política. In: VÁRIOS AUTORES. A obra teórica de Marx: atualidade, problemas e interpretações. São Paulo, Xamã, 2000.

[1] Este texto, ora revisado e atualizado, foi originalmente intitulado "Setor Informal": ação complementar às políticas de assistência ou expressão da acumulação flexível?.

[2] Professora do Departamento de Serviço Social da UFAL.

[3] Abordagem discutida por Salama \& Valier (1997).

[4] Trata-se de uma fábrica (Kao Lin) de confecção de roupas em jeans, que está funcionando numa região conhecida como Maciço de Baturité, aproximadamente a 70 quilômetros de Fortaleza. Essa empresa contrata apenas a mão-de-obra mais especializada, subcontratando toda aquela que se encarrega da montagem das peças, através de cooperativas. Estas não foram criadas pelos cooperados, mas como parte de um grande projeto de industrialização proposto pelo governo cearense. Os "cooperados" são trabalhadores (mulheres, na maioria) que 'foram chamados a participar de uma organização que já estava estruturada para servir aos propósitos de uma empresa capitalista" (Moreira, 1999: 134). As condições ambientais são precaríssimas; as jornadas de trabalho são indefinidas; a disciplina é rígida e desumana, sendo estabelecida pelos proprietários da fábrica. Embora não haja a relação compra/venda da força de trabalho, é evidente que os "cooperados" fazem parte do trabalho coletivo da indústria. Entretanto, de acordo com a legislação brasileira, não há vínculo entre a cooperativa e seus cooperados, nem entre estes e seus tomadores de serviços, com o que se oferece a possibilidade de mobilizar grandes volumes de força de trabalho, para compor o trabalhador coletivo, mediante relações informais, que beiram à escravidão, como se pode ver neste caso. (Idem). 